\title{
A Homeowner-Based Methodology for Economic Analysis of Energy-Efficiency Measures in Residences
}

\author{
Nelson Fumo, Roy Crawford \\ The University of Texas at Tyler, Tyler, USA \\ Email:nfumo@uttyler.edu, rcrawford@uttyler.edu
}

Received March 26, 2013; revised April 26, 2013; accepted May 20, 2013

Copyright (c) 2013 Nelson Fumo, Roy Crawford. This is an open access article distributed under the Creative Commons Attribution License, which permits unrestricted use, distribution, and reproduction in any medium, provided the original work is properly cited.

\begin{abstract}
Residential energy-efficiency measures, besides energy savings, provide opportunities for improvement of thermal comfort, air quality, lighting quality, and operation. However, all these benefits sometimes are not enough to convince a homeowner to pay the incremental cost associated with the energy-efficiency measure. The objective of this work is to develop a methodology for the economic evaluation of residential energy-efficiency measures that can simplify the economic analysis for the homeowner while taking into consideration all factors associated with the purchase, ownership, and selling of the house with the energy-efficiency measure. The methodology accounts for direct and indirect economic parameters associated to an energy-efficiency measure; direct parameters such as the mortgage interest and fuel price escalation rate, and indirect parameters such as savings account interest and marginal income tax rate. The methodology also considers different cases based on the service life of the energy-efficiency measure and loss of efficiency through a derating factor. To estimate the market value, the methodology uses the future energy cost savings instead of the cost of the EEM. Results from the methodology offer to homeowner annual net savings and net assets. The annual net savings gives the homeowner a measure of the annual positive cash flow that can be obtained from an energy-efficiency project; but more important, the net assets offer a measure of the added net wealth. To simplify and increase the use of the methodology by homeowners, the methodology has been implemented in an Excel tool that can be downloaded from the TxAIRE's website.
\end{abstract}

Keywords: Methodology for Economic Analysis; Energy-Efficiency Measures for Residences; Energy Savings in Residences

\section{Introduction}

According to the U.S. Energy Information Administration, the residential sector, with $23 \%$ of the total energy consumption in the United States, compares significantly with the energy consumption of the other sectors: commercial (19\%), industrial (31\%), and transportation (28\%) [1]. Therefore, efforts at all levels are constantly supported by the government in order to promote energy efficient homes.

Energy used in buildings is a multi-variable phenomenon. The variables can be grouped into four categories: users, equipment, construction material, and weather. The study of how the variables in each of the categories affect the energy consumption offers the opportunity to decrease energy use without affecting the activities of the occupants and their thermal comfort. Users/occupants will be willing to adjust their energy use patterns when the benefits are tangible. Although technical matters can be improved, the economic aspect is always a major factor for decision making. Therefore, residential energy efficiency projects should be treated as a financial investment and the attractiveness of a project depends upon the return expected by the owner or investor. Thus, an appropriate economic analysis is a key factor to show the actual potential benefits of the investment which can be highlighted when environmental benefits are also illustrated.

Approaches from different authors to perform economic analysis on residential energy efficiency projects show their similarities. Martinaitis et al. [2] mention calculations of payback time, net present value, internal rate of return, and the cost of conserved energy (CCE) as approaches relatively easy to use for appraisal of renovation in residential buildings. In their proposal of separating investments into those related to energy efficiency improvements, and those related to building renovation, they use the CCE for the appraisal of energy efficiency 
investments. The CCE takes into consideration both the lifespan of measures and the cost of borrowing money. Sadineni et al. [3] develop cost benefit data to be used by a local electric utility in defining a rebate program to encourage energy efficient construction in the Desert Southwest region of the USA. Benefit/cost analysis was performed and payback periods were calculated. Payback period is commonly used because is easy to understand by people of any background. However, although the payback period is a valid economic metric, it leaves out the analysis other economic parameters considered in the proposed methodology. Gorgolewski [4] uses the "savings-to-investment ratio" (SIR) to rank predicted savings from retrofit investments. The SIR is defined as the ratio of the present value of the total life time energy savings and the investment cost, with the present value computed by discounting of all future savings to their equivalent present value. It can be noticed that the SIR is the inverse of the payback period. Ouyang et al. [5] performed life-cycle cost economic analysis to evaluate energysavings effects on thermal simulations. They accounted for initial and maintenance costs, as well as the electricity rates. However, they did not account for added costs due to the interest rate on the loan for the initial and maintenance investment alleging that those costs can be counteracted or exceeded by the increased value of the property due to rapid economic development in China. Lekov et al. [6] presented the method used to conduct the life-cycle cost (LCC) and payback period analysis for gas and electric storage water heaters. The LCC accounted for consumer expenses during the life of an appliance, including equipment, installation, and operating costs (expenses for energy use, maintenance, and repair). To compute LCCs, they discounted future operating costs using a rate that reflects rates in various debt or asset classes that might be used to purchase the appliance. For new construction installations, the discount rate reflects after-tax real mortgage rates. The payback period is calculated using the change in purchase cost (normally higher) at a higher efficiency level, divided by the change in annual operating cost (normally lower). Ouyang et al. [7] used a standard life-cycle cost analysis to conduct economic analysis of upgrading residential buildings in China. The net present value and simple payback time were used to evaluate the investigated retrofits. Fixed loan interest rate, inflation rate, and an increase of electricity price were used for the economic analysis.

It is the opinion of the authors that most of the economic analysis does not account for all the factors involved in the life-cycle cost analysis from a homeowner point of view. Therefore, this paper introduces the methodology being developed at the Texas Allergy, Indoor Environment and Energy (TxAIRE) Institute [8] Re- search and Demonstration Houses to perform economic analysis of energy-efficiency measures (EEM's). This methodology has been developed with the purpose of accounting for all relevant economic factors and criteria in order to offer homeowners with a real and understandable economic analysis for decision making regarding residential EEM's. To simplify and promote the use of the methodology, it has been implemented in an Excel tool that is available from the TxAIRE's website. Throughout this paper, although some terminology are given in terms that a prospective owner can use to evaluate an EEM through the economic analysis of the entire house, the methodology is more oriented to be used for the incremental evaluation of a single EEM. Analysis of a single EEM for new houses or retrofits can be done by knowing the required information for the EEM and the reference case that the project will be compared with. This means that the project can be evaluated through incremental costs and benefits (savings) when the EEM is compared with a reference house without the EEM.

Using the methodology of Taylor et al. [9] as a reference, the authors consider that the following characteristics of the methodology introduce value to a homeowner's economic analysis: 1 ) beyond cash flows the net savings are more truthful to illustrate the economic benefits of the EEM; 2) the net assets illustrate the added net wealth of the homeowner if the EEM is implemented; 3) the methodology considers the market value based on future energy cost savings instead of the cost of the EEM; 4) the methodology proposes analysis of EEM's that have useful service life equal or lower than the house service life; 5) the methodology allows considering other parameters such as reduction of energy costs due to an energy efficiency derating factor, finance of the initial cost through mortgage and/or savings, and impact of savings account interest, and the methodology also allows to illustrate the cumulative benefits in case the homeowners want to consider selling the house in a year that is lower than the period of analysis.

\section{TxAIRE Research and Demonstration Houses}

The Texas Allergy, Indoor Environment and Energy (TxAIRE) Institute [8] was created to be a catalyst for the identification, development, demonstration, evaluation and promotion of technology products that improve the energy efficiency and indoor environmental quality of buildings. The TxAIRE Research and Demonstration Houses have been designed to serve as realistic test facilities for developing and demonstrating new technologies related to energy efficiency, indoor air quality, and sustainable construction materials and methods. The TxAIRE Houses are fully instrumented testbeds, making 
possible full testing and analyses of roof, wall, window, and slab building envelope components. All mechanical systems are also fully instrumented, and include multiple systems to facilitate comparison of performance. The potential of TxAIRE houses to demonstrate and promote technology for energy use reduction in the residential sector suggest the need for a consistent methodology for the economic evaluation of the tested technologies.

\section{Residential Energy Efficiency Projects}

The concept of Net-Zero Energy Homes can be considered as the ultimate goal of energy efficiency projects. However, the high cost associated with this kind of projects is a drawback for its implementation beyond few cases such as homes located in remote areas or owners really committed to the environment. If energy efficiency projects are treated as a financial investment, the attractiveness of residential energy efficiency projects depends upon the return expected by the prospective owner or investor. The estimated return from the investment is computed using economic parameters and the energy used to satisfy the occupants activities and thermal comfort. Energy efficiency projects can be evaluated individually since the cost-benefit varies from one to another alternative. However, several energy efficiency projects can be evaluated in conjunction in order to consider the overall cost-benefit from the synergetic effect on energy use.

When accounting for energy use, it is important to be aware that the efficiency of equipment may decrease over time due to normal wear, and replacement of technology often implies an increase in efficiency. Due to derating factor of installed technology or increment of efficiency when technology is replaced, the annual energy consumption varies even with constant weather conditions and house operation (occupancy patterns or schedules). Since simulations of energy use usually are given for one-year period, it is assumed that the given annual energy consumption is the average energy consumption for the years considered as period of analysis. As example, BEopt [10] defines the average energy use as the average of the annual energy use over the period of analysis. This is important for the consideration of uncertainty. For the economic analysis presented in this paper, the energy use is considered through the estimated utility bills. The utility bills should account for the average price of fuels (electricity, natural gas, etc.) for the first year of analysis and the energy consumption obtained in the same way and conditions for the projects to be compared.

\section{Previous Definitions}

The methodology proposed in this paper is intended to cover all significant scenarios of economic outflows and inflows associated with buying and owning of a house during the defined period of analysis, as well as considering the option of selling the house at any year during the period of analysis. Therefore, for better understanding of the use of some parameters in the proposed methodology, some definitions are given.

\subsection{Period of Analysis}

Period of analysis refers to the number of years the economic analysis will be performed. Although the useful life of a house can be more than a hundred years, shorter periods of analysis decrease the uncertainty on the actual performance of components, advances in technology on replacements, and variation of economic parameters with time. For residential projects a reference period of analysis can be 30 years since it is a common period for mortgage loan and allows accounting for equipment replacement. Since service life of equipment may be shorter than the period of analysis of an energy efficiency residential project, Table 1 shows some examples of service life estimates that can be used as a comparison reference when considering a thirty year period of analysis.

\subsection{Inflation}

Inflation is a familiar concept of money value change over time. It is well understood that most things that are bought today or most services received today will cost more in the future because of the inflation, which also means that money loses purchasing power. LCC analysis can be done by considering cash flows in constant dollars (purchasing power does not change over time) or in current or nominal dollars (actual purchasing power for the year the cash flows are expected to occur in the future). The NIST Handbook 135 [13] recommends analysis with constant dollars using two methods to arrive at constant dollars amounts in an LCCA:

Method 1: "Estimate future costs and savings in constant dollars and discount with a 'real' discount rate, i.e., a discount rate that exclude the rate of inflation."

Method 2: "Estimate future costs and savings in current dollars and discount with a 'nominal' discount rate,

Table 1. Service life estimates of residential equipment.

\begin{tabular}{cc}
\hline Equipment & Median Service Life (years) \\
\hline $\begin{array}{c}\text { Residential single or splitair } \\
\text { conditioning [11] } \\
\text { Residential air-to-air heat } \\
\text { pump [11] }\end{array}$ & 15 \\
Hot-water heater [11] & 15 \\
Solar PV modules [12] & 20 \\
\hline
\end{tabular}


i.e., a discount rate includes the rate of inflation.”

Polly et al. [14] use Equation (1) to model cash flows others than loan payments such as annual utility bill costs, replacement costs in the future, and residual values. The cash flows are inflated according with the estimated inflation $\left(i_{i}\right)$ based on the year $(j)$ the cash flow will occur,

$$
F_{j}=P V \cdot\left(1+i_{i}\right)^{j}
$$

where $F_{j}$ is the cash flow at current dollars at the end of year $j$ and $P$ is the cash flow at current dollars at the beginning of the period of analysis.

\subsection{Discount Rate}

The discount rate is an interest rate used to discount future cash flows to the present value. In general, the discount rate considers the possible growth of available money because of earnings, the risk or uncertainty of the anticipated future cash flows, and the variation in purchasing power due to inflation. Roberts [15], point out that for homeowners the appropriate discount rate depends on their particular financial circumstances giving as reference "The discount rate should be the APR (Annual Percentage Rate) of the highest risk-adjusted rate of return that you can obtain by investing your money, or the lowest rate at which you can borrow money, whichever is higher". In the same order of ideas, Lawrence [16] suggests two discount rates as references for residential real estate analysis. The first one is the Treasury Inflation-Protected Securities (TIPS) that can be used by the buyer as an alternative investment that, although has a very low interest rate, it is a risk-free investment guaranteed to grow with the rate of inflation. The second one is to use the interest rate on the loan used to acquire the property. Eliminating interest expense provides a return on investment, as money not spent, equal to the interest rate on the loan.

Since market interest rates consider the general inflation, they are normally used as nominal discount rates. To compute the real discount rate $\left(i_{d r}\right)$, Equation (2) can be used when the nominal discount rate $\left(i_{d}\right)$ and inflation $\left(i_{i}\right)$ are known.

$$
i_{d r}=\frac{1+i_{d}}{1+i_{i}}-1
$$

\subsection{Escalation Rate}

The escalation rate allows estimating the annual change in the price levels of the goods and services to occur in the future. Since price change for home-related items other than fuels have a zero relative price change ([13], pg. 3-13), the price escalation rate for all non-energyrelated items is equal to the general inflation and there- fore the real escalation rate is zero. The increase of goods or services with time, due to the escalation rate, it can be computed as a compound interest rate as shown in Equation (3)

$$
F_{j}=P V \cdot\left(1+i_{e}\right)^{j}
$$

When the escalation rate of the item in analysis is different from the general inflation, a real escalation rate can be computed using Equation (4) as

$$
i_{e r}=\frac{1+i_{e}}{1+i_{i}}-1
$$

Since technologic development can make a future cost lower than the present cost, such as have happened with computers, a real price escalation rate can be negative. In this case, the future cash flow can be lower than the present cash flow even in presence of inflation.

\subsection{Replacement Costs}

An energy efficiency project may have a useful life lower than the period of analysis, which is particularly true for equipment (e.g. heating and cooling equipment) when compared with the useful life of a house. Therefore, cash flows associated with equipment replacement must be adjusted based on the assumed inflation between the beginning of the analysis period and the time of replacement using Equation (1).

In the process of obtaining the energy use (e.g. simulations), it should be taken into consideration that equipment is replaced with minimum standard efficiency equipment or the same equipment, whichever is more efficient [14].

\subsection{Market Value}

In real state, several definitions may exist for market value. For example,

1) Market value is generally defined as the price a willing buyer would pay a willing seller for a property in its present condition with neither buyer nor seller under pressure to act (such as career relocation, death of a family member, divorce, etc.) [17].

A number of factors may affect a residential property's market value, including:

- External characteristics - “curb appeal”, home condition, lot size, popularity of an architectural style of property, water/sewage systems, sidewalk, paved road, etc.

- Internal characteristics-size and number of rooms, construction quality, appliance condition, demonstrated "pride of ownership", heating type, energy efficiency, etc.

- Supply and demand-the number of homes for sale versus the number of buyers; how quickly the homes 
in your area sell, and

- Location-desirability for a particular school district, neighborhood, etc.

2) Market value is the price at which a particular house, in its current condition, will sell within 30 to 90 days [18].

This definition contains three elements:

- Particular house

- Current condition

- 30 to 90 days

In the same order of ideas, Braun [19] identifies four components to understand a real property market: demand, relationship between supply and demand, competition, and marketability. Since this study focuses on how properties with energy-efficiency characteristics are compared to others for the same market conditions, only the marketability is of interest. Marketability is defined as "the relative desirability of a property in comparison with similar or competing properties in the area," with the value defined as the desire expressed in an economical concept on a monetary basis [19]. For this study, as illustrated later, a reference market value for the energy-efficiency measure is estimated based on the future energy savings discounted with an effective mortgage rate.

\section{Economic Analysis Methodology}

The proposed methodology is based on the incremental cost and benefits of a house with an EEM when compared with the same house without the EEM. The approach that the houses are the same means that the EEM does not change the appearance of the house.

With similar opinion from Ouyang et al. [5], the authors consider that normally the house price is related to what a prospective owner sees or perceives from a house when compared with other houses available in the market for the present economic conditions. This suggests that details on aspects such as efficiency of components and remaining life expectancy of components are not properly considered or understood. The authors also consider that market value generally accounts only for an economic analysis that is mainly based on the initial investment. Since a better economic analysis should account for cash flows (positive and negative) associated with purchasing, owning, and selling a house over the period of analysis, the economic analysis of an EEM should be made based on the net assets at any year during the period of analysis.

\subsection{Previous Considerations}

- Although an EEM may not increase parameters normally affecting the computations of property taxes (square footage, heating and cooling area, etc.), it may increase the relative cost when compared with another house without the EEM, thus a property tax may still apply.

- The annual initial estimated utility bill is increased for all years by the nominal fuel price escalation rate. It is recalled that the nominal price escalation rate accounts for general inflation. The escalation rate is assumed to be constant over the period of analysis.

- The annual initial estimated incremental maintenance cost associate with the EEM is adjusted annually by the general inflation rate.

- The residual value of the EEM is assumed to be zero at the end of its service life.

- A derating factor is used to decrease the energy cost savings in order to account for any decrease of efficiency of the technology over time. When the service life of the EEM compares with the service life of the house (for example walls insulation), the derating factor is neglected.

- The EEM initial cost should account for all expenses associated with the implementation of the project. For example, if a mortgage is being requested only for the cost of the project (not for the house itself) or a fraction of the closing costs can be associated to the project, these closing costs should be added to the actual cost of the project.

\subsection{Methodology}

The developed methodology allows the estimation of the homeowner's assets, at any year for the period of analysis, as consequence of the implementation of an EEM. Therefore, the computations performed through the methodology are based on the incremental value of cash flows as result of the implementation of the EEM. In other words, all computations are performed as the difference in cash flows when a house with an EEM is compared with a reference house that does not have the EEM.

As justified in Section 4, the methodology uses 30 years as a reference period of analysis; which is related to the common maximum mortgage term. However, the service life of energy-efficiency measures forces the consideration of two cases. One case relates to EEMs with service lives that compare with the service life of the house; for example, wall insulation and windows. The other case relates to EEMs with service lives that are shorter than the service life of the house. This case involves mainly equipment; for example, heating and cooling systems. For practical purposes on the implementation of the methodology as illustrated in Section 5.3, the maximum service lives of EEMs with service lives lower than the service life of the house is limited to 30 years.

For cases when the service life of the project is shorter than the service life of the house, results must be interpreted according to the technology being analyzed. This 
implies two options of analysis based on the replacement of the technology. The replacement option should be considered for technologies that must be replaced; for example, heating and cooling systems. The no-replacement option should be considered for technologies that do not necessarily need to be replaced; for example, solar photovoltaic systems. For the option that the technology must be replaced, the period of analysis is reduced to the service life of the project. This is because a new analysis should be done at the replacement year to account for variation in equipment efficiency and variation of technology cost other than inflation. For the option that the technology need not be replaced, although the energy savings and project market value become zero at the end of the service life, the analysis must be completed for the mortgage term if this is greater than the service life. This is done to account for the impact of mortgage payments on the net assets associated to the project.

To estimate the homeowner's assets for the implementation of an EEM, the following computations are needed. As reference, these computations are presented in the order they were implemented in the Excel Tool developed for the implementation of the proposed methodology. The Excel Tool is described in Section 5.3 and it can be downloaded free of charge from the TxAIRE's website.

\subsubsection{Mortgage}

The down payment $(D P)$ is defined based on a down payment rate $\left(r_{d p}\right)$ over the initial cost of the EEM $(C)$ as shown in Equation (5).

$$
D P=C \cdot r_{d p}
$$

Thus, the initial mortgage $(M)$ is computed as

$$
M=C \cdot\left(1-r_{d p}\right)=C-D P
$$

As for standard analysis of mortgages, the fix annual mortgage payment $(A)$ can be estimated for each year $(j)$ as

$$
A_{j}=M \cdot \frac{i_{m} \cdot\left(1+i_{m}\right)^{n_{m}}}{\left(1+i_{m}\right)^{n_{m}}-1}
$$

where $i_{m}$ is the annual mortgage rate and $\left(n_{m}\right)$ is the mortgage term in years. However, since mortgage payments are equal monthly payments, in order to increase the accuracy of the computations from Equation (7), the equation needs to be modified to account for the monthly payments as

$$
A=M \cdot \frac{i_{m} \cdot\left(1+i_{m} / 12\right)^{12 j}}{\left(1+i_{m} / 12\right)^{12 j}-1}
$$

The mortgage interest $(M I)$ for each year of analysis are calculated based on the unpaid mortgage principal $(P)$ of the previous year as shown in Equation (9).

$$
M I_{j}=P_{j-1} \cdot i_{m}
$$

where the unpaid mortgage principal is computed as

$$
P_{j}=P_{j-1}-\left(A_{j}-M I_{j}\right)
$$

Equations (9) and (10) indicate that the mortgage principal decreases faster as payments are made. This is important because the assets during the period of analysis are affected by the mortgage monthly payment which is an aspect considered by the methodology.

\subsubsection{Energy Cost Savings}

The energy cost savings $(S)$ are computed as the product of the estimated energy savings and the fuel price. It changes over the years $(j)$ because the energy savings can be reduced if a derating factor $\left(r_{d}\right)$ is considered and because the price of the fuel changes with the fuel price escalation rate $\left(i_{f}\right)$. Equation (4) can be used to obtain the nominal fuel escalation rate from a real fuel escalation rate $\left(i_{f r}\right)$. If the estimated first year energy cost savings $\left(S_{1}\right)$ is computed using the estimated energy savings from energy simulations and the estimated average cost of fuels (electricity and/or natural gas) for the first year, $S$ for any year can be calculated using Equation (11). In Equation (11), the energy savings are assumed to decrease linearly during the EEM service life $\left(n_{l}\right)$.

$$
S_{j}=S_{1} \cdot\left[1-(j-1) \frac{r_{d}}{n_{l}-1}\right] \cdot\left(1+i_{f}\right)^{(j-1)}
$$

In Equation (11), $n_{l}-1$ is used since the first year energy savings is estimating at the nominal efficiency.

\subsubsection{Maintenance Cost}

Annual maintenance cost $(M C)$ associated to the EEM is increased by inflation $\left(i_{i}\right)$ during the years $(j)$ of service life as

$$
M C_{j}=M C_{1} \cdot\left(1+i_{i}\right)^{j-1}
$$

where $M C_{1}$ is the first year maintenance cost.

\subsubsection{Mortgage Tax Savings}

Since mortgage interest $(M I)$ are tax deductible, mortgage tax savings (MTS) are achieved at the rate of the marginal income tax rate $\left(r_{t}\right)$ as

$$
M T S_{j}=M I_{j} \cdot r_{t}
$$

\subsubsection{Property Tax}

Although an EEM may not affect the parameters considered to estimate the value of a house for taxes purpose, local or state property taxes must be considered if the 
incremental cost of the house is taxable. To account for the increase in cost of the EEM that may affect the property value for tax purposes, the EEM cost is increased over the years with the general inflation rate. Equation (14) is used to account for property taxes (PT) associated to the EEM according with a property tax rate $\left(r_{p t}\right)$ and inflation.

$$
P T_{j}=C \cdot\left(1+i_{i}\right)^{j} \cdot r_{p t}
$$

\subsubsection{Annual Net Savings}

Annual net savings (NS) refers to the direct benefits expected from the implementation of the EEM. This net savings is cash that will be added or deducted (if it is the case) from the savings account; which affects the homeowner's net assets. As shown in Equation (15), the project net savings is computed based on the energy cost savings, mortgage tax savings, annual mortgage payment, maintenance cost, and the effective property tax. Effective property tax $\left(P T_{j} \cdot\left(1-r_{t}\right)\right)$ is used since the property tax can be deducted from the income tax.

$$
N S_{j}=S_{j}+M T S_{j}-A_{j}-M C_{j}-P T_{j} \cdot\left(1-r_{t}\right)
$$

Project net savings is one of the two parameters to be reported and considered by the homeowner for decision making on the implementation of the EEM. Therefore, in order that the homeowner can compare options on today dollars, net savings for each year along the useful life of the EEM are adjusted using the general inflation rate as the discount rate.

$$
A N S_{j}=N S_{j} \cdot\left(1+i_{i}\right)^{-j}
$$

\subsubsection{Savings Account}

Savings account balance ( $S A)$ takes into consideration the cumulative incremental net savings. As mentioned, the down payment is considered as a withdrawal from the saving account at the beginning of the analysis. Thus, the down payment will cause an initial negative incremental balance on the savings account.

The savings account is increased or decreased by the project net savings, but the balance on the previous year is also affected by the savings interest rate $\left(i_{s}\right)$. On the other hand, since the earned interests are taxable, the marginal income tax rate must be applied to the earned interests. Equation (17) shows how the balance on the savings account is computed from the balance of previous year $(j-1)$.

$$
S A_{j}=S A_{j-1} \cdot\left[1+i_{s}\left(1-r_{t}\right)\right]+N S_{j}
$$

\subsubsection{EEM Market Value}

The EEM market value $(M V)$ is computed as the future energy cost savings increased according to the fuel price escalation rate (electricity, natural gas, etc.) and discounted using an effective mortgage rate $\left(i_{m e}\right)$ (mortgage rate after tax). An effective mortgage rate, Equation (18), is used since it is the actual cost of borrowing money for the implementation of the EEM.

$$
i_{m e}=i_{m} \cdot\left(1-r_{t}\right)
$$

Since the EEM market value is estimated based on future energy cost savings, two analyses arise based on the EEM service life. When the EEM's service life is lower than the service life of the house, the market value for each year is estimated based on the remaining years of the service life as shown in Equation (19a). When the EEM's service life compares with the service life of the house, the market value for each year must be estimated based on a specific number of years the energy savings will be projected $\left(n_{s}\right)$ and the market value can be estimated using Equation (19b). Although any reasonable number of years may be used, the mortgage period can be used as a reference for the analysis. The mortgage period is suggested as a reference because it will be the period of analysis a prospective owner may use if the house is put up for sale.

$$
\begin{gathered}
M V_{j}=S_{j+1} \cdot \frac{1+i_{f}}{i_{m e}-i_{f}}\left[1-\left(\frac{1+i_{f}}{1+i_{m e}}\right)^{n_{l}-j}\right] \\
M V_{j}=S_{j+1} \cdot \frac{1+i_{f}}{i_{m e}-i_{f}}\left[1-\left(\frac{1+i_{f}}{1+i_{m e}}\right)^{n_{s}}\right]
\end{gathered}
$$

From Equation (19), it can be noticed that the market value at the end of year $j$ is computed based on the estimated energy cost savings of the following year $(j+1)$. This is done since the house market value at the beginning of the year $j+1$ must reflect the savings that can be achieved during this year.

\subsubsection{Net Assets}

The EEM net asset (NA) value is a measure of the added net wealth of the homeowner if the EEM is implemented. The net assets are computed based on the amount of cash the owner will have in the savings account if the house is sold at the market value and the mortgage principal is paid off. Equation (20) shows how the net assets are computed.

$$
N A_{j}=M V_{j}-P_{j}+S A_{j}
$$

In Equation (20), the incremental market value is based on the future energy cost savings of the EEM. However, it does not reflect anything about housing market variations, but this does not introduce an error on the computation of the incremental assets. This is justified since the EEM does not change the appearance of 
the house. In other words, the market value of two houses with the same appearance and construction characteristics will change similarly under the same housing market. However, the actual market value of the house with the EEM should reflect the benefits from the EEM. It must be understood that the net assets computed with Equation (20) is based on the expectation that the house can be sold at year $j$ at the estimated market value. If the house is sold for less than the estimated market value, the net assets would be decreased proportionally.

Project net assets are the second parameter to be reported and considered by the homeowner for decision making on the implementation of the EEM. Therefore, in order that the homeowner can compare options on today dollars, net assets for each year along the useful life of the EEM are adjusted using the general inflation rate as the discount rate.

$$
A N A_{j}=N A_{j} \cdot\left(1+i_{i}\right)^{-j}
$$

\section{Excel Tool}

The methodology has been implemented in an Excel tool. The tool is available at the TxAIRE's website and it can be downloaded free of charge. As mentioned, the methodology proposes two parameters to be used by the homeowner for decision making on the implementation of the EEM. An example of the two parameters, net savings and net assets adjusted by inflation, are illustrated in Figure 1 and Figure 2, respectively. Figure 1 shows the net savings obtained at a specific year at dollars that reflect the current purchase power. It can be seen as the net cash flow that may happen at that year after accounting for costs and energy savings. Figure 2 shows the incremental net assets of the homeowner. It indicates the actual incremental wealth, at dollars that reflect the current purchase power, of the homeowner if the house is sold at any of the years. It reflects the cumulative net assets through the years.

Results illustrated in Figure 1 and Figure 2 were obtained using the following parameters:

Energy-Efficiency Measures (EEM)

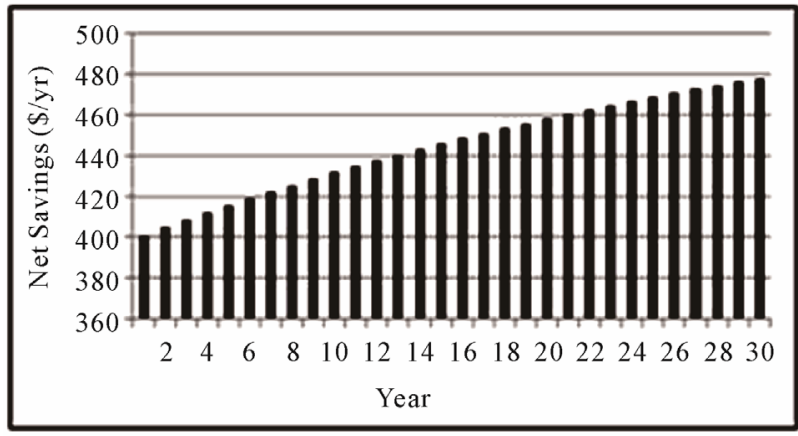

Figure 1. Net savings adjusted by inflation.

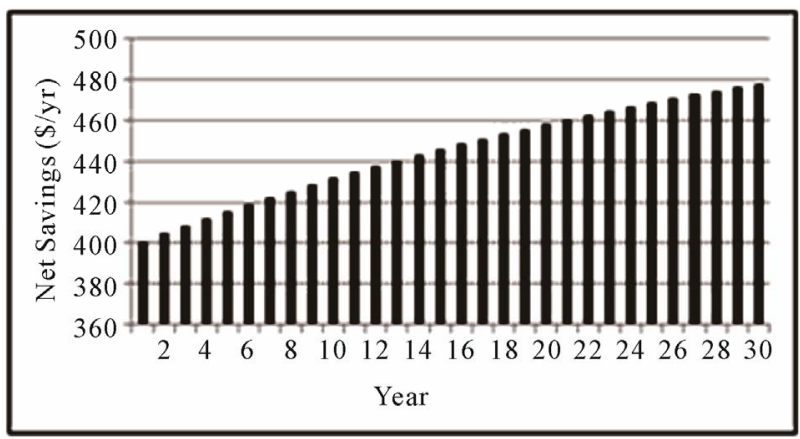

Figure 2. Net assets adjusted by inflation.

Initial cost (\$): 4000

First year energy cost savings (\$): 600

First year maintenance cost $(\$)$ : 0

Efficiency derating factor (\%): $0.00 \%$

Service life equal to house life: TRUE

Time limit for energy savings (yr): 25

Fuel

Fuel escalation rate (\%): $2.50 \%$

Mortgage

Down payment rate (\%): $0.0 \%$

Down payment (\$): 0

Mortgage (\$): 4000

Mortgage term (yr): 30

Mortgage rate (\%): $4.00 \%$

Annual mortgage payment (\$): 229

Effective mortgage rate (\%): $3.00 \%$

Other factors

General inflation rate (\%): $2.50 \%$

Marginal income tax rate (\%): $25.00 \%$

Property tax rate (\%): $0.00 \%$

Savings interest rate (\%): $1.00 \%$

\section{Conclusion}

Government agencies and professional organizations such as the American Society of Heating, Refrigerating and Air-Conditioning Engineers (ASHRAE) are working on different strategies to promote and develop technology and legislation (code, standards, etc.) to address energy use in residences. Nontraditional construction material and new technology, especially renewable energy technology, are well accepted as means for energy use reduction but their higher initial investment has been a drawback. Therefore, analysis involving all of the economic parameters as well as hidden benefits must be available for homeowners in the decision making process. The methodology presented in this paper has a homeowner point of view given as resulting annual net savings and cumulative annual incremental assets. The incremental assets obtained from the implementation of the energy-efficiency measure is a metric of the added net wealth of the homeowner if the house is sold at the esti- 
mated market value computed based on the future energy cost savings. To simplify and promote the use of the methodology, it has been implemented in an Excel tool free of charge.

\section{REFERENCES}

[1] The U.S. Department of Energy, “Annual Energy review 2010,” Energy Information Administration. http://205.254.135.7/totalenergy/data/annual/pdf/aer.pdf

[2] V. Martinaitis, E. Kazakevicius and A. Vitkauskas, “A Two-Factor Method for Appraising Building Renovation and Energy Efficiency Improvement Projects,” Energy Policy, Vol. 35, No. 1, 2007, pp. 192-201. doi:10.1016/j.enpol.2005.11.003

[3] S. B. Sadineni, T. M. France and R. F. Boehm, "Economic Feasibility of Energy Efficiency Measures in Residential Buildings,” Renewable Energy, Vol. 36, No. 11, 2011, pp. 2925-2931. doi:10.1016/j.renene.2011.04.006

[4] M. Gorgolewski, "Optimizing Renovation Strategies for Energy Conservation in Housing," Building and Environment, Vol. 30, No. 4, 1995, pp. 583-589. doi:10.1016/0360-1323(95)00011-T

[5] J. L. Ouyang, J. Ge and K. Hokao, "Economic Analysis of Energy-Saving Renovation Measures for Urban Existing Residential Buildings in China Based on Thermal Simulation and Site Investigation,” Energy Policy, Vol. 37, No. 1, 2009, pp. 140-149. doi:10.1016/j.enpol.2008.07.041

[6] A. Lekov, V. Franco, S. Meyers, L. Thompson and V. Letschert, "Energy Efficiency Design Options for Residential Water Heaters: Economic Impacts on Consumers,” ASHRAE Transactions, Las Vegas, January 2011, pp. 103-110.

[7] J. L. Ouyang, M. J. Lu, B. Li, C. Y. Wang and K. Hokao, "Economic Analysis of Upgrading Aging Residential Buildings in China Based on Dynamic Energy Consumption and Energy Price in a Market Economy," Energy Policy, Vol. 39, No. 9, 2011, pp. 4902-4910. doi:10.1016/j.enpol.2011.06.025

[8] The University of Texas at Tyler, "The Texas Allergy, Indoor Environment and Energy (TxAIRE)”. www.2.uttyler.edu/txaire/

[9] T. Taylor, N. Fernandez and R. Lucas, "Methodology for Evaluating Cost-Effectiveness of Residential Energy Code Changes,” Pacific Northwest National Laboratory, 2012.

[10] National Renewable Energy Laboratory (NREL), "Building Energy Optimization Software (BEopt),” 2012. http://beopt.nrel.gov

[11] 2011 ASHRAE Handbook, HVAC Applications.

[12] A. W. Czanderna and G. J. Jorgensen, “Accelerated Life testing and Service Lifetime Prediction for PV Technologies in the Twenty-First Century," National Renewable Energy Laboratory, 1999. www.nrel.gov/docs/fy99osti/26710.pdf

[13] S. K. Fuller and S. R. Petersen, "Life-Cycle Costing Manual for the Federal Energy Management Program,” NIST Handbook 135, 1995 Edition. www1.eere.energy.gov/femp/program/lifecycle.html

[14] B. Polly, M. Gestwick, M. Bianchi, R. Anderson, S. Horowitz, C. Christensen and R. Judkoff, “A Method for Determining Optimal Residential Energy Efficiency Retrofit Packages,” U.S. Department of Energy, Energy Efficiency and Renewable Energy, Building Technology Program, 2011.

http://www1.eere.energy.gov/library/default.aspx?page=2 \&spid=2

[15] J. Ritchter, "Financial Analysis of Residential PV and Solar Water Heating Systems,” 2009. http://www.michigan.gov/documents/dleg/Thesisforweb_ 283277_7.pdf

[16] L. D. Roberts, "The Appropriate Discount Rate for Residential Real Estate Analysis,” Ezinearticles, 2012.

[17] The New York State Department of Taxation and Finance, "How to Estimate the Market Value of Your Home." 2012.

http://www.tax.ny.gov/pubs_and_bulls/orpts/mv_estimate s.htm

[18] J. Vaughan, “What Is Market Value?” Creative Real Estate Online, 2012. http://www.creonline.com/what-is-market-value.html

[19] D. A. Braun. "An Introduction to Market Components and Interactions,” The Appraisal Journal, Vol. LXXXI, No. 1, 2013, pp. 63-73. 


\section{Nomenclature}

General:

EEM: Energy Efficiency Measure

$F$ : Future cash flow

$j$ : Index for year of economic analysis

Cost parameters for EEM’s (\$):

$A$ : Mortgage payment (annual)

ANA : Adjusted net assets

ANS : Adjusted annual net savings

$C:$ Initial cost

$D P$ : Down payment

$M$ : Initial mortgage amount

$M C$ : Maintenance cost

$M I$ : Mortgage interest

$M V$ : Market value

MTS : Mortgage tax savings

$N A$ : Nominal net assets

$N S$ : Nominal annual net savings

$P$ : Mortgage principal

$P V$ : Present value

$P T$ : Property tax

$S$ : Energy cost savings

$S A$ : Savings account balance
Annual economic rates (non-dimensional):

$i_{d}$ : Nominal discount rate

$i_{d r}$ : Real discount rate

$i_{e}$ : Escalation rate

$i_{e r}$ : Real escalation rate

$i_{f}$ : Nominal fuel price escalation rate

$i_{f r}$ : Real fuel price escalation rate

$i_{i}$ : General inflation rate

$i_{m}$ : Nominal mortgage rate

$i_{m e}$ : Effective mortgage rate

$i_{s}$ : Savings interest rate

Other factors (non-dimensional):

$r_{d}$ : Efficiency derating factor

$r_{d p}$ : Down payment rate

$r_{p t}$ : Property tax rate

$r_{t}$ : Marginal income tax rate

Time parameters (years):

$n_{m}$ : Mortgage term

$n_{l}$ : Service life of the EEM

$n_{s}$ : Time limit for future energy savings 